\title{
The Role of Mathematics Education in Helping to Produce a Data Literate Society
}

\author{
William Finzer
}

\section{Report}

There were 30 participants from 17 countries. The challenge presented to the group was as follows: "The data revolution is everywhere except the classroom. In general, students finish their schooling seriously under-prepared to participate in the emerging data-driven society. This represents an enormous loss of scientific discovery, solutions to social problems, economic advancement, ...."

Organizers Co-chairs: William Finzer (USA), Cliff Konold (USA); Team Members: Maxine Pfannkuch (New Zealand), Michiko Watanabe (Japan), Yuan Zhiquiang (China); Liasion IPC Member: Yuriko Baldin Yuriko (Brazil).

W. Finzer $(\square)$

KCP Technologies, Emeryville, USA

e-mail: bfinzer@kcptech.com

(C) The Author(s) 2015 


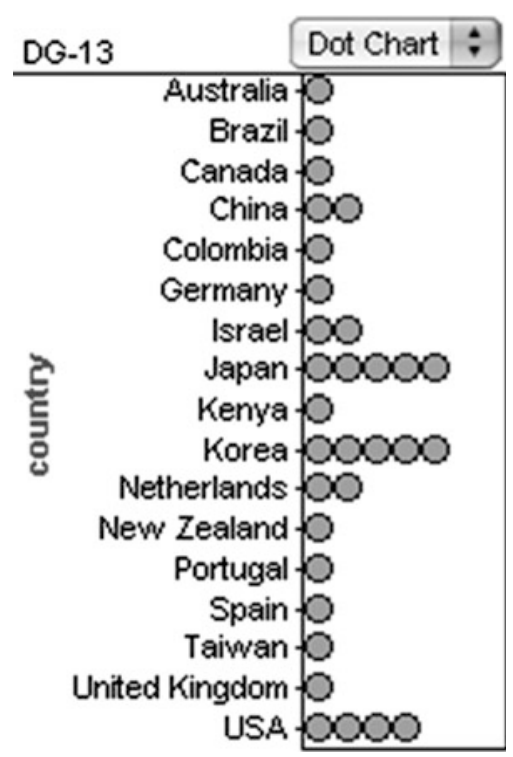

\section{Highlights from Participants' Introductory Comments}

- Biggest challenge in Kenya is infrastructure, so there is lack of computers and other technology.

- There is a new program in Portugal to try to emphasize statistical ideas in the early years, however the teachers do not have the knowledge to be able to implement this currently.

- One specific topic in Brazil in general education is data handling, but teachers do not know what it means. There is a new program to introduce data handling to master's students who will be teachers.

- One of the difficulties in Columbia is the different goals among different groups in the country. For example, government versus teacher goals. And the curriculum does not match what is happening in the schools.

- Students are underprepared not just technically, but ideologically. The problem with thinking that if data is on the web, then it's true. The other problem is if you believe in something strongly enough, then you don't need any data.

- Students in Korea explain interpretations very superficially. They are good at computing, but it's difficult for them to do data analysis.

- There is statistical literacy in the curriculum in New Zealand. The students start to talk about their own data, then critique other's data. In high school, it moves to looking at media reports and so on. The challenge is professional development for the teachers because they are not used to having these discussions in the classrooms. 
- In China, probability and statistics have been content areas since 1978, but they haven't become the focus area until the new curriculum standards in 2001 and 2003. Teachers will now pay much attention to probability and students might get high scores in examination, but still not be able to solve authentic problems.

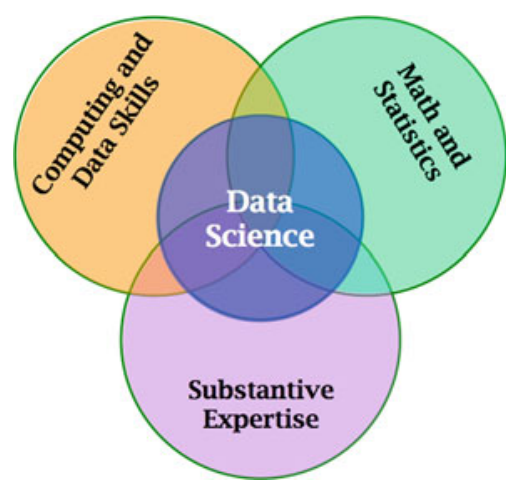

\section{Highlights from Discussion of "Regarding the Problem, to What Extent Is What We Are Talking About Something that Goes Beyond 'the Need for More and Better Statistics Education?"'}

- The expansion of statistic education should be manipulation of data, raising critical issues about data, and critiquing data.

- We are looking for boundary crossing between different perspectives including statistical education, heuristics (e.g. representativeness, availability, anchoring, etc.), and responsible critical social perspectives.

- It is not enough to teach more and better statistics in terms of computations. We think students need to be able to communicate, tell a story, and explain their interpretation. There needs to be something else in terms of communication.

- What is taught currently in schools in statistics is too narrow. It is just calculations that even when taught well, is still too narrow. (For example, archival of data is something that statisticians do not think about it, but in economics it is important. Also data cleaning. $90 \%$ of the effort is spent in the data cleaning area, with very little time spent in data analysis.) 


\section{Highlights from Discussion of "What Strengths Do \\ Mathematics and Statistics Educators Bring to Bear \\ on the Problem? Conversely, with What Aspects \\ of the Problem Are Mathematics and Statistics Educators \\ Unlikely to Bring Expertise?"}

- ability to think quantitatively, defining algebraic expressions, handicap-fear of there not being a right answer

- statistics is one part of mathematics in china, the mathematics teacher is the statistics teacher, statisticians are teaching statistics only, don't consider statistics at school level, good statistical knowledge but don't know how to teach at school level, guide the curriculum design, how to teach have no idea (lecturers)

- know the concepts of scientific enquiry (PPDAC), statisticians know the more concrete of the cycle, huge data and how to handle huge data, important and big role for statistics for big data age

- mathematics doesn't use context, statistics brings context, conflict. Is this content mathematics or social studies? PISA had a strong effect on what to teach in mathematics

- basic concepts in statistics no longer have the same status, huge data sets, different types of data, introduce students to different types of data, how to talk about signal of data, how to present the data, need to work at global level, how do we sample our global data, the basic ideas need to be revisited - data analysis, not statistics as this is an old word

- students learn statistics in the mathematics classroom so always want to know the right answer, "so what is the answer", this is a problem, look at decision making in a comparison situation

- society is not necessarily data driven but there is a flood of data.

\section{Highlights from Discussion of "What Should Be the Role of Mathematics Education in Helping to Produce a Data Literate Society?"}

- classrooms-Active engagement of students in the investigative process (PPDAC), importance of technology in teaching and learning statistics - creating the displays etc. so can focus on interpretation, also to build conceptual development, exploring outliers as an example.

- concepts - Variation and prediction, sample as a starting point, where does data come from, what is data, very important to have simple counting procedures and also by deciding what to measure, defining difficult variables and this is crucial for validity, ordinal and other scales. 
- policy - What are the key ideas that we need to keep and/or build that we will always need; what do we have to change what we are doing in our classrooms? Ethical issues, big data not always available to all citizens, open data sets being available to all; statistics across the curriculum; look for New Zealand example and follow (blindly) cognizant of the local situation-collaboration amongst statisticians, educators and teachers in leading the reform in the curriculum; may need to collaborate with other disciplines, collaborate with internet experts, data people, computer experts and create discipline of data science.

Open Access This chapter is distributed under the terms of the Creative Commons Attribution Noncommercial License, which permits any noncommercial use, distribution, and reproduction in any medium, provided the original author(s) and source are credited. 